Daniel Santos Martins ${ }^{1,2}$

(D) https://orcid org/0000-0001-6084-9987

Thiago Pacheco de Almeida Sampaio $0^{1,2}$

@ittps://orcid.org/0000-0003-3879-1541

Francisco Lotufo Neto 1,2

Onttps://orcid.org/0000-0002-2043-7643

\section{Relationships between worry and depressive symptoms during two group therapies for generalized anxiety disorder}

\author{
A inter-relação entre preocupações e sintomas depressivos \\ em adultos com ansiedade generalizada
}

DOI: $10.1590 / 0047-2085000000361$

\begin{abstract}
Objective: Generalized anxiety disorder (GAD) is a chronic and disabling disorder associated with various impairments and shows a significant prevalence in the worldwide and Brazilian populations. This study aimed to investigate the longitudinal relationship of two symptoms relevant to the disorder (worry and depressive symptoms) in the context of a randomized clinical trial (RCT) by using a cross-lagged panel model (CLPM) analysis. Methods: A total of 92 adult patients with GAD were randomized to receive ten sessions of either acceptance-based group behavioral therapy (ABBT) or nondirective supportive group therapy (NDST). Treatment had four time-point measures. Worries were measured using the Penn State Worry Questionnaire (PSWQ), and depression was measured using the Depression Anxiety Stress Scales (DASS-D). Results: The NDST model revealed significant paths from worry to depression (first wave) and from depression to worry (second wave). There was no other significant cross-lagged effect. These data show that there was an influence between symptoms only during one of the treatment groups, and without a homogeneous and constant pattern in any of the cross-lagged routes. Conclusion: A supportive group psychotherapy potentially interferes with the pattern of the direct relationship between worries and depressive symptoms in adults with GAD.
\end{abstract}

\section{KEYWORDS}

Anxiety, anxiety disorders, worry, depression, psychotherapy.

\section{RESUMO}

Objetivo: $O$ transtorno de ansiedade generalizada (TAG) é um diagnóstico crônico e incapacitante, associado a diversos prejuízos e com relevante prevalência na população mundial e na brasileira. Este estudo tem por objetivo investigar a relação longitudinal de duas manifestações relevantes para o transtorno (preocupação e sintomas depressivos), utilizando uma análise cross-lagged panel model (CLPM) por meio de dados de um ensaio clínico randomizado (ECR). Métodos: Um total de 92 pacientes adultos com TAG foi randomizado para duas psicoterapias em grupo: terapia comportamental baseada em aceitação (TCBA) ou terapia de apoio não diretiva (TAND). Cada grupo teve duração de 10 sessões, distribuídas em 14 semanas. O tratamento teve quatro tempos de medida: linha de base, meio do tratamento, pós-tratamento e seguimento de três meses. As variáveis investigadas foram: preocupações, medidas pelo Penn State Worry Questionnaire (PSWQ), e sintomas depressivos, medidos pela Depression Anxiety Stress Scales (DASS-D). Os modelos CLMP foram gerados pelo programa Mplus. Resultados: $O$ modelo do grupo TAND revelou duas rotas significativas: preocupação para sintomas depressivos (primeira onda) e sintomas depressivos para preocupação (segunda onda). Não houve outro efeito cross-lagged que obteve significância estatística. Esses dados mostram que houve influência alternada entre os sintomas somente durante o período de um dos dois tratamentos testados, configurando um padrão heterogêneo das rotas cross-lagged. Conclusão: A psicoterapia suportiva em grupo potencialmente interfere no padrão da relação direta entre preocupação e sintomas depressivos em adultos com TAG.

\section{PALAVRAS-CHAVE}

Ansiedade, transtornos de ansiedade, preocupações, depressão, psicoterapia.

\footnotetext{
Received in: Mar/31/2021. Approved in: Nov/19/2021
}

1 Clinical Psychology Program, Institute of Psychology (IP), University of São Paulo, São Paulo, SP, Brazil. 2 Anxiety Disorders Program, Institute of Psychiatry (IPq), University of São Paulo, São Paulo, SP, Brazil.

Address for correspondence: Daniel Santos Martins. Rua Dr. Ovídio Pires de Campos, 785, Cerqueira César - 05403-903 - São Paulo, SP, Brasil. E-mail:dsm209@gmail.com

O ECR foi registrado em clinicaltrials.gov: 51363615.4 . 0000.0068/NCT03930095. 


\section{INTRODUCTION}

Generalized anxiety disorder (GAD) is a major psychiatric pathology, with lifelong prevalence of 3.7\% worldwide and $5.1 \%$ in the Brazilian population, with the latter accounting for the highest rate in Latin America'. GAD is considered to be a chronic and disabling disorder, associated with significant impairments in quality of life and increased costs of healthcare services ${ }^{2,3}$.

Chronic and uncontrollable worrying is the core symptom of $\mathrm{GAD}^{4}$. Worries make up a chain of thoughts or images laden with negative affetcs ${ }^{5}$, even though they are not necessarily bad since they represent a natural phenomenon affecting, to a greater or lesser degree, all human beings. However, worries are a prominent component in the etiology and maintenance of GAD according to several clinical models ${ }^{6}$. Moreover, in addition to GAD, worries are hypothesized as a possible core process of various pathologies in the DSM; and they are associated with symptoms of stress, anxiety, and depression?

Depression is often among the variables categorized as outcome measures in clinical studies on individuals with $\mathrm{GAD}^{8}$. This is part of a major field of investigation in mental health, which is focused on the relationship between anxiety and depression ${ }^{9}$. The comorbidity of GAD and major depressive disorder (MDD) is reported as the most prevalent not only among anxiety and mood disorders, but also among DSM-5 diagnoses'. By the way, there is some debate in the literature about them representing stages of a single pathology ${ }^{10}$, to the point of suggesting the unification of these diagnoses into a new category ${ }^{11}$.

By virtue of the strong presence of worries and depression in individuals with GAD, this study sought to investigate the bidirectional relationship between these symptoms in a context of psychotherapies. Clinical trials have produced evidence favorable to the improvement of both these sets of symptoms in individuals with GAD? . However, as stated by Kazdin ${ }^{12}$, it is still necessary to try to better understand clinical improvement processes and the relationship among their constituting variables. To this end, our proposal is to use a cross-lagged panel model (CPLM), which is a method for analyzing longitudinal panels when a single set of variables is repeatedly measured on multiple occasions $^{13}$. Research studies using CLPM relate two or more variables over time, usually for exploratory research, with the main objective of examining causality through the directional influence between those variables ${ }^{14}$. Therefore, this study aims to find: (a) whether there is an influence between worries and depression in individuals with GAD over the course of psychotherapeutic treatments; and, if so, (b) what the sign of this influence is; and (c) which of them is causally dominant.

\section{METHODS}

This research is a secondary study of a larger project that resulted in a controlled randomized clinical trial (RCT) assessing the efficacy of an acceptance-based group behavioral therapy (ABBT) in comparison with a nondirective supportive group therapy (NDST) for adults with GAD ${ }^{15}$. The project was approved by the institutional review board of the University of São Paulo (USP), and all its main stages were carried out at a mental health center (named Institute of Psychiatry - $(\mathrm{Pq})$, which is part of the largest regional public hospital in Brazil, located in the city of São Paulo. By comparing two means of PSWQ and three other clinical outcome measures, a sample size of 92 was calculated to be sufficient for the RCT from which our data were collected. A power of 80\%, a 2-tailed $a=.05$, and an anticipated dropout rate of about $25 \%$ were considered. Psychotherapy sessions and main data collection took place in 2016. In the present study, therefore, we used a portion of the collected data to examine the relationship between worries and depressive symptoms longitudinally in both groups.

The RCT was registered on clinicaltrials.gov: 51363615.4 . 0000.0068/NCT03930095. The registration was made retrospectively due to a mistake in the registration process. The study was conducted under the Declaration of Helsinki and Ethical Guidelines for Clinical Studies and was approved by the research ethics committee of the Medical School of the USP, Brazil.

\section{Participants}

After the IPq advertised to the university hospital patients and in media outlets, some hundreds of people were screened before 92 of them were considered eligible to participate in the study. They were equally randomized to join either group: ABBT or NDST. Randomization was stratified based on use of psychotropic medication at the time. Inclusion criteria were to be (a) aged between 18 and 65 years; (b) literate in Portuguese; (c) on a stable dose of medication in the previous three months (only those receiving pharmacological treatment); and (d) primarily diagnosed with GAD according to the Mini International Neuropsychiatric Interview (MINI - Brazilian version 5.0.016), which is based on the diagnostic criteria of the DSM-IV-TR or ICD-10. The exclusion criteria were (a) to be receiving psychotherapy during the screening period and (b) to meet the diagnostic criteria for bipolar disorder, psychosis, substance dependence, or high suicide risk (according to MINI).

Table 1 below presents the main demographic characteristics of the sample. Participants were 36.6 years old on average (standard deviation: 12.4), were predominantly single ( $n=54 ; 58 \%$ ), and most of them were not taking medication ( $n=59 ; 64 \%$ ) at the beginning of the study. Consistent with the literature on GAD ${ }^{17,18}$ the number of 
women was roughly three times as large as that of men ( $n=68 ; 73,9 \%$ ), and the most common diagnostic comorbidity was MDD ( $n=56 ; 60,9 \%)$. A quite noticeable piece of data was the high number of participants attending university or with higher education ( $n=64 ; 69,5 \%)$, a rate much higher than the Brazilian average of $17 \%{ }^{19}$. All participants provided informed consent for the study. Please refer to Sampaio et al..$^{15}$ for access to the CONSORT flow diagram.

\section{Procedures}

Both treatments consisted of 10 two-hour sessions over 14 weeks: the first six sessions were weekly and the last four, fortnightly. ABBT group sessions were guided by a protocol adapted from the individually applied original version tested in some clinical trials for adults with $G A D^{20}$. ABBT is, therefore, an evidence-based therapy, with features similar to those of traditional cognitive behavioral therapies (CBTs).

Due to an ethical and institutional principle of not conducting an RCT with a non-intervention arm, as is the case in studies using a waiting list, another type of therapy with evidence of efficacy for the treatment of GAD was provided: a supportive psychotherapy ${ }^{21}$, represented by the NDST group. The focus of this group was on the so-called common factors of psychotherapy, such as empathic listening, building a therapist-patients alliance, and therapeutic optimism² ${ }^{22}$. All sessions were audio-recorded and, based on them, trained independent raters assessed that both groups displayed good adherence.
All 92 patients were allocated to four ABBT groups and four NDST groups. Each group was conducted by one therapist and one cotherapist. All professionals were clinical psychotherapists.

\section{Measures}

Assessment was conducted in four time points: pretreatment (Week 0), midtreatment (Week 6), posttreatment (Week 14), and 3-month follow-up (Week 26). All clinical data have been stored in the Research Electronic Data Capture (REDCap ${ }^{23}$ ) software, a digital tool used by USP for research in healthcare. For this study, we selected the data from the instruments measuring worries and depressive symptoms.

The Penn State Worry Questionnaire (PSWQ ${ }^{24}$ ) is a 16-item self-report questionnaire aimed at assessing generalized pathological worries. Each instrument item is assessed on a Likert scale, ranging from 1 (not at all typical of me) to 5 (very typical of me). The higher the total score, the higher the level of pathological worries. The PSWQ is the most established instrument to assess worries in clinical populations ${ }^{25}$, and the researcher used its edition translated into Brazilian Portuguese ${ }^{26}$. Sampaio et al..$^{15}$ found a good internal consistency at the four time points: $0.91,0.89,0.90$, and 0.92 .

The Depression Anxiety and Stress Scale - Short Form (DASS-2127) is a 21 -item self-report questionnaire divided into three factors: Depression (items: 3, 5, 10, 13, 16, 17, and 21), Anxiety (items: $2,4,7,9,15,19$, and 20), and Stress (items:

Table 1. Socio-demographic and clinical variables for both groups

\begin{tabular}{|c|c|c|c|}
\hline & Total $(n=92)$ & NDST $(n=46)$ & ABBT $(n=46)$ \\
\hline \multicolumn{4}{|l|}{ Gender } \\
\hline Female & 68 (73.9\%) & $34(73.9 \%)$ & $35(76 \%)$ \\
\hline Male & $24(26.1 \%)$ & $12(26.1 \%)$ & $11(24 \%)$ \\
\hline Age, mean (SD), y & $36.6(12.4)$ & $34.8(10.6)$ & $38.4(13.8)$ \\
\hline \multicolumn{4}{|l|}{ Education: } \\
\hline Elementary school: & $2(2.2 \%)$ & $0(0.0 \%)$ & $2(4.3 \%)$ \\
\hline Post-high School: & $26(28.3 \%)$ & $14(30.4 \%)$ & $12(26.1 \%)$ \\
\hline Higher education: & $64(69.5 \%)$ & $32(69.6 \%)$ & $32(69.6 \%)$ \\
\hline \multicolumn{4}{|l|}{ Family status: } \\
\hline Married/de facto: & $23(25.0 \%)$ & $13(28.3 \%)$ & $10(21.7 \%)$ \\
\hline Single /separated: & $69(75.0 \%)$ & $33(71.7 \%)$ & $36(78.3 \%)$ \\
\hline Curent psychiatric Treatment: & $33(35.9 \%)$ & $16(34.8 \%)$ & 17 (36.9\%) \\
\hline \multicolumn{4}{|l|}{ Comorbid disorders: } \\
\hline Major depressive disorder (MDD) & $56(60.9 \%)$ & $28(60.9 \%)$ & $28(60.9 \%)$ \\
\hline Panic disorder (PD) & $38(41.3 \%)$ & $17(37.0 \%)$ & $21(45.7 \%)$ \\
\hline Agoraphobia & $26(28.3 \%)$ & $16(34.8 \%)$ & $10(21.7 \%)$ \\
\hline Social phobia & $19(20.7 \%)$ & $11(23.9 \%)$ & $8(17.4 \%)$ \\
\hline Obsessive compulsive disorder (OCD) & $5(5.4 \%)$ & $2(4.3 \%)$ & $3(6.5 \%)$ \\
\hline Post-traumatic stress disorder (PTSD) & $4(4.3 \%)$ & $1(2.2 \%)$ & $3(6.5 \%)$ \\
\hline
\end{tabular}

Note - ABBT: acceptance-based group behavioral therapy; NDST: nondirective supportive group therapy; no significant differences were found between groups on any variable at the $p<.05$ level. 
$1,6,8,11,12,14$, and 18). The answer options for each item vary between 0 (did not apply to me at all) to 3 (applied to me very much, or most of the time). For this study, only the DASS-D subscale was used, given the objective of relating worries to depressive symptoms. It is recommended to use each subscale separately instead of their sum as a unified factor ${ }^{28}$; and the DASS-D is mentioned in the literature as equivalent to the BDI-II scale ${ }^{29}$. The Brazilian Portuguese version of the scale was used ${ }^{30}$. Sampaio et al..$^{15}$ found a good internal consistency at the four assessment time points: $0.89,0.87,0.90$, and 0.89 .

\section{Statistical analyses}

Descriptive statistics were calculated using the R program ${ }^{31}$ to characterize our sample. After that, we used a CLPM to examine the bidirectional relationship between worry and depressive symptoms during the course of treatments. The Mplus Version 8.032 was used to run the CLPM (Figure 1), and the syntaxes are available upon request. To our main analysis, we used the Bayesian estimation, which is advantageous to small sample sizes and that has point estimates and credible intervals $(\mathrm{Cls})$ as the principal parameter estimates ${ }^{33}$. Model fit was assessed using confidence intervals and the posterior predictive $p$ value, with values close to .50 representing excellent-fitting models $s^{34}$.

Missing data were substantial: the dropout rates were $54.3 \%(n=25)$ for ABBT and 50\% $(n=23)$ for NDST. The Bayesian estimation allowed agreement with the intention to treat (ITT) principles establishing that all randomized subjects should be analyzed ${ }^{35}$. We therefore treated the $34.6 \%$ of missing data as fewer observations per subject.

The CLPM model is composed of synchronous effects (i.e., correlations between worry and depression at each time point), stability effects (i.e., effects of each variable at time $t$ on the same variable at time $t+1$ ), and cross-lagged effects (i.e., the effect of a symptom at time $t$ on the other symptom at time $t+1$ ), with the last representing the main results of the model.

\section{RESULTS}

Table 2 presents the sample characteristics through the four measurement times, the descriptive statistics for the observed worry and depression variables, and the twotailed Spearman correlations matrix for both groups. More moderate to strong correlations ${ }^{36}$ were found in NDST group.

Two CLPMs were run separately, one for each group. According to Muthén and Asparouhov ${ }^{34}$, the model fit information we obtained indicates an excellent model fit for ABBT (PPP $=0.5 ; \mathrm{Cl}:-26.47-49.37$ ) and a good model fit for ABBT (PPP $=0.34 ; \mathrm{Cl}:-20.56-48.65)$.

Each model ran 12 regressions and four covariances simultaneously. The diagrams of the generated CLPMs and all the main standardized values (i.e., estimates and credible intervals) are shown in figure 2. In Bayesian estimation, 95\% credible intervals $(\mathrm{Cls})$ are used as the main reference to treat paths as significant, which indicate a 95\% probability that the population value falls within the limits of the credible interval ${ }^{37}$. To increase readability error terms in contemporaneous effects in the second and third waves were omitted in figure 2.

Each generated model resulted in a different pattern. In the autoregressive paths, only the NDST model showed significance in all three waves of one variable: worries ( $\beta$ :607-.741). According to Kearney ${ }^{14}$, smaller autoregressive coefficients mean less stability or influence from the previews time point. Therefore, our results indicate less stability of both variables in the ABBT model during treatment time points, and a similar pattern for the depression autoregressive rout in the NDST model.

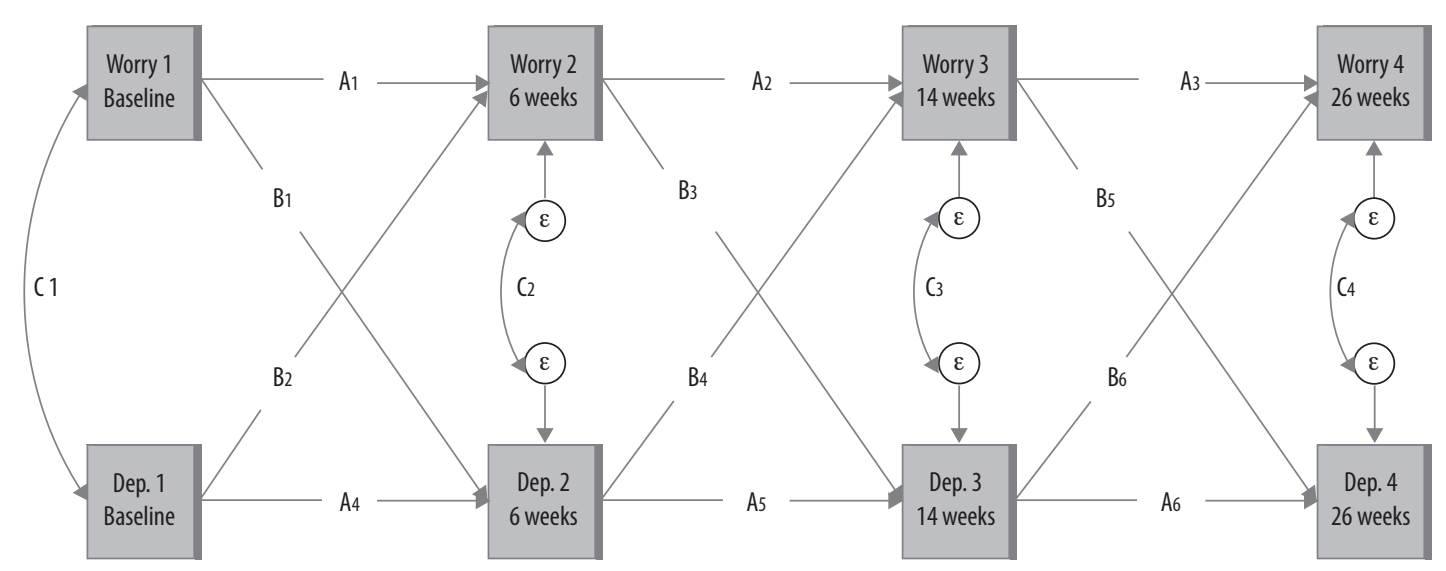

Figure 1. Diagram of cross-lagged panel model examining relationships between worry and depression.

Note - Squares: observed variables; A: autoregressive/stability path; B: cross-lagged path; C: synchronous correlations; $\varepsilon$ : measurement erros; 6 weeks: midtreatment; 14 weeks: posttreatment; 26 weeks: 3-month follow-up. 
Table 2. Descriptive statistics and spearman's matrix correlations of the observed variables used in the CLPM

\begin{tabular}{|c|c|c|c|c|c|c|c|c|c|c|c|}
\hline Variable & D1 & D2 & D3 & D4 & P1 & P2 & P3 & P4 & N & Mean & SD \\
\hline \multicolumn{12}{|c|}{ Group ABBT } \\
\hline D1 & 1.00 & & & & & & & & 46 & 15.74 & 10.24 \\
\hline D2 & 0.263 & 1.00 & & & & & & & 34 & 13.35 & 9.15 \\
\hline D3 & $.434^{*}$ & $.560^{\star *}$ & 1.00 & & & & & & 21 & 9.52 & 11.12 \\
\hline D4 & $.443^{*}$ & $.599^{\star \star}$ & $.530^{\star}$ & 1.00 & & & & & 21 & 9.52 & 9.92 \\
\hline P1 & $.446^{\star \star}$ & 0.314 & 0.189 & 0.155 & 1.00 & & & & 46 & 66.33 & 11.29 \\
\hline P2 & -0.055 & $.496^{\star \star}$ & 0.258 & 0.054 & $.368^{*}$ & 1.00 & & & 34 & 60.47 & 8.48 \\
\hline P3 & 0.077 & $.488^{*}$ & 0.095 & 0.255 & 0.427 & $.499^{\star}$ & 1.00 & & 21 & 53.10 & 10.61 \\
\hline P4 & 0.263 & $.518^{*}$ & $.509^{\star}$ & 0.313 & 0.282 & $.558^{*}$ & $.723^{\star \star}$ & 1.00 & 20 & 55.55 & 9.68 \\
\hline \multicolumn{12}{|c|}{ Group NDST } \\
\hline D1 & 1.00 & & & & & & & & 46 & 16.91 & 10.72 \\
\hline D2 & $.389^{\star}$ & 1.00 & & & & & & & 27 & 11.41 & 9.72 \\
\hline D3 & $.472^{*}$ & $.691^{* *}$ & 1.00 & & & & & & 23 & 11.57 & 8.82 \\
\hline D4 & $.415^{\star}$ & $.782^{\star \star}$ & $.766^{\star \star}$ & 1.00 & & & & & 23 & 16.00 & 10.58 \\
\hline P1 & $.489^{\star *}$ & $.453^{*}$ & 0.291 & 0.333 & 1.00 & & & & 46 & 66.15 & 9.91 \\
\hline P2 & 0.142 & $.563^{\star \star}$ & 0.286 & $.491^{*}$ & $.654^{\star \star}$ & 1.00 & & & 27 & 64.93 & 10.15 \\
\hline P3 & 0.156 & $.705^{\star \star}$ & $.503^{\star}$ & $.604^{\star *}$ & $.702^{\star \star}$ & $.791^{\star \star}$ & 1.00 & & 23 & 62.04 & 10.20 \\
\hline P4 & 0.039 & $.569^{\star \star}$ & $.467^{\star}$ & $.520^{\star}$ & $.718^{\star \star}$ & $.808^{\star \star}$ & $.906^{\star \star}$ & 1.00 & 23 & 63.65 & 11.68 \\
\hline
\end{tabular}

Note - N: sample size; W: worry measured by PSWQ; D: depressive symptoms measured by DASS-D; D.1/W.1: week 0 (baseline); D.2/W.2: week 6 (midtreatment); D.3/W.3: week 14 (posttreatment); D.4/W.4: week 26 (3-month follow-up).

* Significant at the 0.05 level (2-tailed).

** Significant at the 0.01 level (2-tailed).
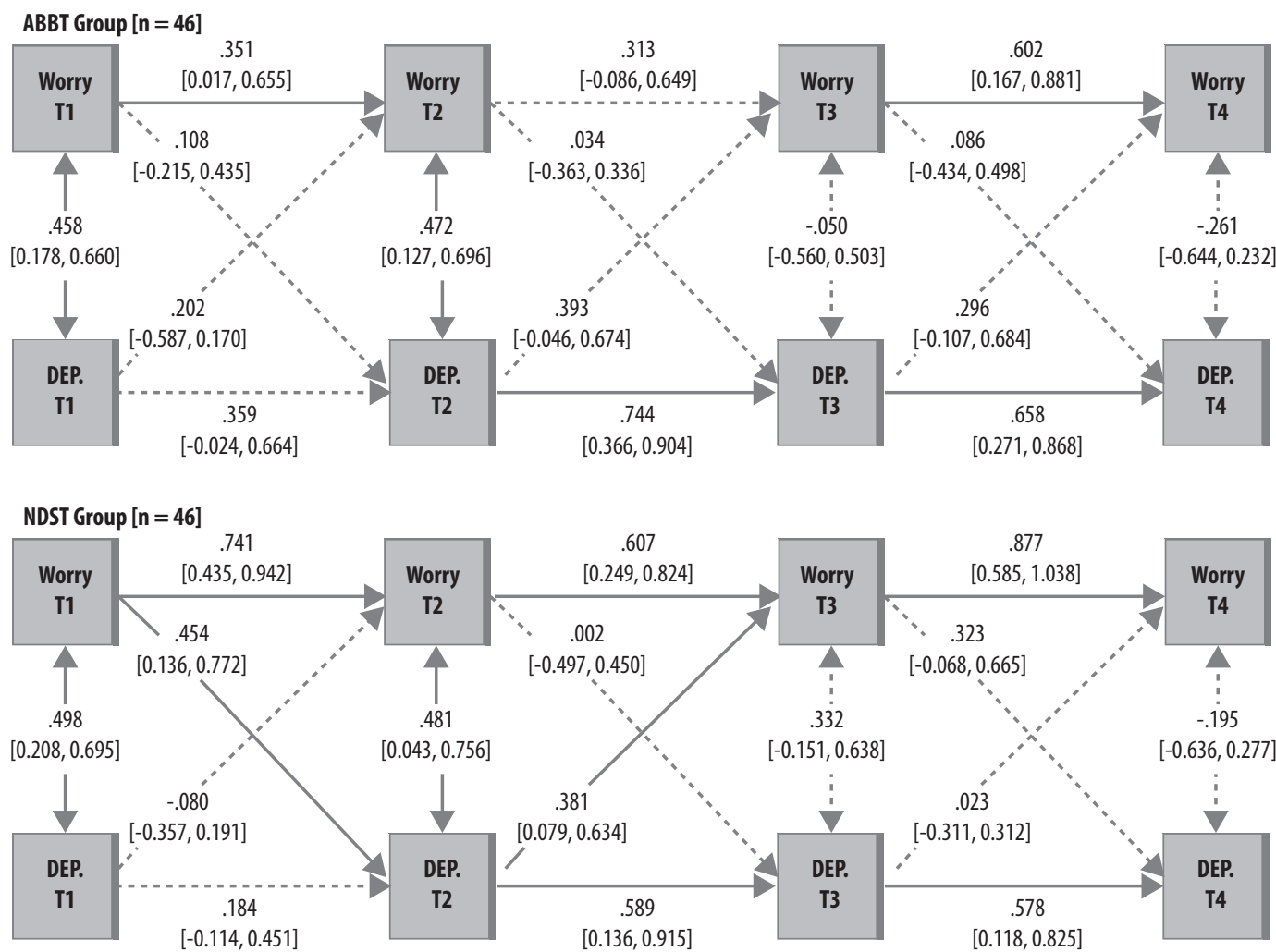

Figure 2. Final CLPM model for ABBT and NDST groups.

Note - T1: baseline; T2: midtreatment (week 6); T3: posttreatment (week 14); T4: 3-month follow-up (week 26); numbers represent standardized point estimates ( $\beta$ ) and 95\% credible intervals (inside parenthesis); dotted pathways are nonsignificant (i.e., Cl did contain 0). 
In both NDST e ABBT models there were significant correlations between PSWQ and DASS-D score results in the baseline and between their residual errors at week 6 . These data suggest that the trajectories of worries and depressive symptoms followed each other only before and in the first part of the treatments.

In the cross-lagged routes, the main results of a CLPM, only NDST model showed significant regressions: worry to depression in the first wave $(\beta=0.454 ; \mathrm{Cl}=0.136-0.772$ ) and depression to worry in the second wave $(\beta=0.381 ; \mathrm{Cl}$ $=0.079-0.634)$. These results suggest that baseline PSWQ scores predicted DASS-D at week 6 (mid-treatment), and DASS-D at week 6 predicted PSWQ scores at week 14 (posttreatment). In sum, we found a relationship of influence between worries and depressive symptoms, and vice versa, but only during NDST period of treatment, since there was no significant cross-lagged regression in the last wave. The sign of the significant pathways were both positive and we found limited data for the aim of knowing which of them was causally dominant.

\section{DISCUSSION}

The nature of the association between anxiety and depression remains unclear, despite their well-established co-occurrence, and there are significant unresolved responses about the longitudinal and temporal relationships between them ${ }^{38}$. The present study represents a perspective within this theme since it explores the specific relationship between worries and depressive symptoms in the context of an RCT with two psychotherapies for GAD. According to the bibliographic research we conducted for this study, there has been no published investigation into this relationship using a cross-lagged analysis.

From the results obtained, we found that the variables influence each other, but only during the NDST intervention, and the sign of influence between them was positive, indicating that changes in one of the symptoms accompany changes in the other, with the same sign (i.e., if one improves, so does the other). However, determining which route (worries to depression or vice versa) is causally dominant is more difficult due to the heterogeneity of the two significant paths found in both models. Since the term causality is less frequently used than influence or prediction even in studies showing homogeneity of any route ${ }^{39}$, this study will follow similar research in which there were "pieces" of significance in the routes and their focus was on these sections ${ }^{40}$.

Both significant cross-lagged paths in the NDST model have consistency with other studies. Similar to what occurred in the first wave of our model, the longitudinal study using measures of 21 consecutive days by Starr and Davila ${ }^{41}$ found a predictive value of anxious mood and worries for depressive symptoms and anhedonia, respectively. Consistent with the finding of the second wave, of depressive symptoms predicting worries in the period including the second half of the treatment, a data analysis conducted by Aderka et al. ${ }^{42}$ found that depressive symptoms fully mediated changes in GAD symptoms both for individuals with GAD and those with MDD during pharmacological or psychotherapeutic treatment.

Even the alternation of significant cross-lagged paths in the NDST model is similar to the findings in the research by Walderhaug et al. ${ }^{43}$ relating panic symptoms to depression in patients with panic disorder undergoing CBT, indicating that there may be some instability in the influence of anxious and depressive variables over the course of some treatments (as occurred in the NDST).

Because the data in this study come from an RCT, the randomization of the participants allowed us to visualize a picture of the potential interference of the different groups, and the period of follow up, in the route patterns. The relationships of influence of worries and depressive symptoms having appeared only in the NDST model raise the question of which components could explain our findings since the common factors that sustain this treatment are also present in the ABBT groups. Would be possible to specific activities and elements of ABBT "disable" the relationships of worries and depression? Some of ABBT components appear in the literature as relevant mechanisms of influence to both symptoms (e.g., mindfulness skills ${ }^{44}$ ), but others have been specifically designed to impact anxious symptoms (e.g., imaginal exposure ${ }^{45}$ ), which could have interfered in the trajectory of the variables.

However, the absence of significant cross-lagged effects in the last wave of both models could be another indicative that it was the NDST components that resulted in a heterogeneous relationship between worries and depressive symptoms. Further research is required to evaluate possible mechanisms that could explain how supportive therapy might translate to changes in worry and depression over time, and to verify whether a similar pattern of the last wave occurs in adults with GAD in periods of non-treatment.

There is a lack of studies on GAD verifying relations between symptoms using cross-lagged analyses. Research specifically designed to investigate associations between symptoms should be carried out, also including other independent variables, such as pharmacological treatments, or cohort studies. Moreover, in more comprehensive observational studies, a CLPM analysis could verify unaffected patterns of relationship between several symptoms across time in GAD and non-GAD populations (e.g., major depression and high worriers without GAD).

\section{Limitations}

This study is a secondary analysis stemming from a larger RCT ${ }^{15}$. Similar to the investigation by Quigley et al. ${ }^{46}$, the sample size of the RCT on which this study is based was relatively large for 
a clinical study, though modest for a CLPM analysis. Both models we generated obtained appropriate adjustment indices, even though a larger sample would increase confidence in the results. Another important issue regarding sample size was that the number of participants was not sufficient to generate more robust models, such as the Random Intercepts CrossLagged Panel Model (RI-CLPM), an alternative model described by Hamaker et al. ${ }^{47}$ as superior to traditional CLPM. The fact that the four measurement time points were not equidistant, which is recommended to avoid biased interpretations ${ }^{13}$, is still another issue arising from the RCT design on which this study is based. In addition, even though a follow-up time point differentiates the model in this study from other cross-lagged analyses, it would be interesting to have an additional wave generated from two posttreatment time points so as to verify whether patterns found are maintained.

The selection of variables investigated may also be questioned, since worries are a specific symptom that does not make up the breadth of the symptomatology of GAD. Moreover, the absence of a variable related to the components of the interventions in the model, both common factors (e.g., therapeutic alliance) and specific ABBT factors (e.g., psychological flexibility), limits the understanding of the findings.

\section{CONCLUSION}

The present study contributes to the scientific literature on the relationship between anxiety and depression by carrying out a CLPM analysis so far unpublished and cross-lagged investigations based on clinical interventions and RCTs. The results we obtained indicate that there are heterogeneous relationships of influence between worries and depressive symptoms in individuals with GAD, but only with NDST intervention, which is supported by more universal therapeutic principles, may have created an interference in the dynamics of this relationship. We were not able to report on causality, and even on the predominance of any routes, based on the disposition of the results. By avoiding the limitations presented in this research, future studies will be able to assess whether our findings can be generalized and verify the participation of other variables and mechanisms. This can make it possible to advance the understanding of the intricate relationship of GAD with depressive symptoms, the diagnosis of MDD, and other comorbidities.

\section{INDIVIDUAL CONTRIBUTIONS}

Daniel S. Martins - Participated in the design of the study, data collection and curation, data analysis, text construction and article submission.
Thiago P. A. Sampaio - Participated in the design of the study, coordinated data collection and treatment interventions, revised and corrected all major versions of the main text.

Francisco L. Neto - Participated in the design of the study, helped with data analysis, revised and corrected all major versions of the main text.

\section{CONFLICTS OF INTEREST}

Ms Daniel S. Martins and Drs Thiago P. A. Sampaio and Francisco L. Neto declare to have no conflict of interest or financial disclosures related to this work.

\section{ACKNOWLEDGEMENTS}

We would like to thank all the clinicians and colleagues from the Anxiety Disorders Program, AMBAN, for all the support in the major project from which this article is resulting.

\section{DATA AVAILABILITY STATEMENT}

The data that support the findings of this study are available from the corresponding author upon reasonable request.

\section{OTHER INFORMATION}

The first author 16-digit ORCID identifier: 0000-0001-6084-9987.

The full ORCID ID and the link to its public record are https://orcid.org/0000-0001-6084-9987.

\section{REFERENCES}

1. Ruscio AM, Hallion LS, Lim C, Aguilar-Gaxiola S, Al-Hamzawi A, Alonso J, et al (2017). Cross-sectional Comparison of the Epidemiology of DSM-5 Generalized Anxiety Disorder Across the Globe. JAMA Psychiatry. 2017;74(5):465-75.

2. Kessler RC, Aguilar-Gaxiola S, Alonso J, Chatterii S, Lee S, Ormel J, et al. The global burden of mental disorders: an update from the WHO World Mental Health (WMH) surveys. Epidemiol Psichiatr Soc. 2009;18(1):23-33.

3. Bereza BG, Machado M, Einarson TR. Systematic review and quality assessment of economic evaluations and quality-of-life studies related to generalized anxiety disorder. Clin Ther. 2009;31(6):1279-308.

4. Crocq MA. The history of generalized anxiety disorder as a diagnostic category. Dialogues Clin Neurosci. 2017;19(2):107-16.

5. Borkovec TD, Robinson E, Pruzinsky T, DePree JA. Preliminary exploration of worry: some characteristics and processes. Behav Res Ther. 1983;21(1):9-16.

6. Behar E, DiMarco ID, Hekler EB, Mohlman J, Staples AM. Current theoretical models of generalized anxiety disorder (GAD): conceptual review and treatment implications. J Anxiety Disord. 2009;23(8):1011-23. 
7. Kertz SJ, Bigda-Peyton JS, Rosmarin DH, Björgvinsson T. The importance of worry across diagnostic presentations: prevalence, severity and associated symptoms in a partial hospital setting. J Anxiety Disord. 2012;26(1):126-33.

8. Nasiri F, Mashhadi A, Bigdeli I, Chamanabad AG, Ellard KK. Augmenting the unified protocol for transdiagnostic treatment of emotional disorders with transcranial direct current stimulation in individuals with generalized anxiety disorder and comorbid depression: A randomized controlled trial. J Affect Disord. 2020;262:405-13.

9. Hettema JM, Prescott CA, Kendler KS. The effects of anxiety, substance use and conduct disorders on risk of major depressive disorder. Psychol Med. 2003;33(8):1423-32.

10. Huppert JD. Anxiety disorders and depression comorbidity. In: Antony MM, Stein MB, editors. Oxford handbook of anxiety and related disorders. New York, NY: Oxford University Press; 2009. p. 576-86.

11. Watson D. Rethinking the mood and anxiety disorders: a quantitative hierarchical model for DSM-V. J Abnorm Psychol. 2005;114(4):522-36.

12. Kazdin AE. Mediators and mechanisms of change in psychotherapy research. Annu Rev Clin Psychol. 2007;3:1-27.

13. Kuiper RM, Ryan 0. Drawing conclusions from cross-lagged relationships: Re-considering the role of the time-interval. Structural Equation Modeling. 2018;25(4):809-23.

14. Kearney MW. Cross-lagged panel analysis. In: Allen MR, editor. The SAGE encyclopedia of communication research methods. Thousand 0aks, CA: Sage; 2017. p. 312-4.

15. de Almeida Sampaio TP, Jorge RC, Martins DS, Gandarela LM, Hayes-Skelton S, Bernik MA, et al. Efficacy of an acceptance-based group behavioral therapy for generalized anxiety disorder. Depress Anxiety. 2020;37(12):1179-93.

16. Sheehan DV, Lecrubier Y, Sheehan KH, Amorim P, Janavs J, Weiller E, et al. The MiniInternational Neuropsychiatric Interview (M.I.N.I.): the development and validation of a structured diagnostic psychiatric interview for DSM-IV and ICD-10. J Clin Psychiatry. 1998:59(20):22-33.

17. Vesga-López O, Schneier FR, Wang S, Heimberg RG, Liu SM, Hasin DS, et al. Gender differences in generalized anxiety disorder: results from the National Epidemiologic Survey on Alcohol and Related Conditions (NESARC). J Clin Psychiatry. 2008;69(10):1606-16.

18. Kessler RC, DuPont RL, Berglund P, Wittchen HU. Impairment in pure and comorbid generalized anxiety disorder and major depression at 12 months in two national surveys. Am J Psychiatry. 1999;156(12):1915-23.

19. OECD-iLibrary. Education at a Glance 2018: OECD Indicators, OECD Publishing, Paris. 2018. Available from: http://dx.doi.org/10.1787/eag-2018-en

20. Hayes-Skelton SA, Roemer L, Orsillo SM. A randomized clinical trial comparing an acceptance-based behavior therapy to applied relaxation for generalized anxiety disorder. J Consult Clin Psychol. 2013;81(5):761-73.

21. Hunot V, Churchill R, Silva de Lima M, Teixeira V. Psychological therapies for generalised anxiety disorder. Cochrane Database Syst Rev. 2007;(1):CD001848.

22. Markovitz JC. What is Supportive Psychotherapy? Focus. 2014;12;285-9.

23. Harris PA, Taylor R, Thielke R, Payne J, Gonzalez N, Conde JG. Research electronic data capture (REDCap) - a metadata-driven methodology and workflow process for providing translational research informatics support. J Biomed Inform. 2009;42(2):377-81.

24. Meyer TJ, Miller ML, Metzger RL, Borkovec TD. Development and validation of the Penn State Worry Questionnaire. Behav Res Ther. 1990;28(6):487-95.

25. Kumar V, Avasthi A, Grover S. Correlates of worry and functional somatic symptoms in generalized anxiety disorder. Ind Psychiatry J. 2019;28(1):29-36.

26. Castillo CS, Macrini L, Cheniaux E, Landeira-Fernandes J. Psychometric Properties and Latent Structure of the Portuguese Version of the Penn State Worry Questionnaire. Span J Psychol. 2010;13(1):431-43.
27. Lovibond SH, Lovibond PF. Manual for the Depression Anxiety Stress Scales. Psychology Foundation Monograph. Australia: The Psychology Foundation; 1995.

28. Antony M, Bieling PJ, Cox BJ, Enns MW, Swinson RP. Psychometric properties of the 42item and 21-item versions of the Depression Anxiety Stress Scales in clinical groups and community a sample. Psychol Assess. 1998;10:176-81.

29. Gloster AT, Rhoades HM, Novy D, Klotsche J, Senior A, Kunik M, et al. Psychometric properties of the Depression Anxiety and Stress Scale-21 in older primary care patients. J Affect Disord. 2008;110(3):248-59.

30. Vignola RC, Tucci AM. Adaptation and validation of the depression, anxiety and stress scale (DASS) to Brazilian Portuquese. J Affect Disord. 2014;155:104-9.

31. R Core Team. R: A language and environment for statistical computing. R Foundation for Statistical Computing, Vienna, Austria. 2019. Available from: https://www.Rproject.org/

32. Muthén LK, Muthén BO. Mplus User's Guide. Eighth Edition. Los Angeles, CA: Muthén \& Muthén; 1998-2017.

33. Ozechowski TJ. Empirical Bayes MCMC estimation for modeling treatment processes, mechanisms of change, and clinical outcomes in small samples. I Consult Clin Psychol. 2014;82(5):854-67.

34. Muthén B, Asparouhov T. Bayesian structural equation modeling: A more flexible representation of substantive theory. Psychol Methods. 2012;17(3):313-35.

35. McCoy CE. Understanding the Intention-to-treat Principle in Randomized Controlled Trials. West J Emerg Med. 2017;18(6):1075-8.

36. Schober P, Boer C, Schwarte LA. Correlation Coefficients: Appropriate Use and Interpretation. Anesth Analg. 2018;126(5):1763-8

37. Campbell SB, Renshaw KD, Kashdan TB, Curby TW, Carter SP. A Daily Diary Study of Posttraumatic Stress Symptoms and Romantic Partner Accommodation. Behav Ther. 2017;48(2):222-34.

38. Long EE, Young JF, Hankin BL. Temporal dynamics and longitudinal co-occurrence of depression and different anxiety syndromes in youth: Evidence for reciprocal patterns in a 3-year prospective study. J Affect Disord. 2018;234:20-7.

39. Aderka IM, McLean CP, Huppert JD, Davidson, JR, Foa EB. Fear, avoidance and physiological symptoms during cognitive-behavioral therapy for social anxiety disorder. Behav Res Ther. 2013;51(7):352-8.

40. Meyerhoff J, Rohan KJ. Treatment expectations for cognitive-behavioral therapy and light therapy for seasonal affective disorder: Change across treatment and relation to outcome. J Consult Clin Psychol. 2016;84(10):898-906.

41. Starr LR, Davila J. Temporal patterns of anxious and depressed mood in generalized anxiety disorder: a daily diary study. Behav Res Ther. 2012;50(2):131-41.

42. Aderka IM, Beard C, Lee J, Weiss RB, Björgvinsson T. The relationship between depression and generalized anxiety during intensive psychological and pharmacological treatment. J Affect Disord. 2015;184:261-8.

43. Walderhaug EP, Gjestad R, Egeland J, Havik OE, Nordgreen T. Relationships between depressive symptoms and panic disorder symptoms during guided internet-delivered cognitive behavior therapy for panic disorder. Nord J Psychiatry. 2019;73(7):417-24

44. Baker AW, Frumkin MR, Hoeppner SS, LeBlanc NJ, Bui E, Hofmann SG, et al. Facets of Mindfulness in Adults with Generalized Anxiety Disorder and Impact of Co-occurring Depression. Mindfulness. 2019;10:903-12

45. Goldman N, Dugas MJ, Sexton KA, Gervais NJ. The impact of written exposure on worry: a preliminary investigation. Behav Modif. 2007;31(4):512-38.

46. Quigley L, Dozois D, Bagby RM, Lobo D, Ravindran L, Quilty LC. Cognitive change in cognitive-behavioural therapy v. pharmacotherapy for adult depression: a longitudinal mediation analysis. Psychol Med. 2019;49(15):2626-34.

47. Hamaker EL, Kuiper RM, Grasman RPPP. A critique of the cross-lagged panel model. Psychol Methods. 2015;20(1):102-16 